\title{
Fiziksel Engelliliğin Gebelik ve Annelik Üzerine Etkisi
}

\author{
Influence of Physical Disability on Pregnancy and Motherhood
}

\author{
Şükran BAŞGÖL*, Ümran OSKAY**
}

İletişim/Correspondence: Şükran BAŞGÖL Adres/Adress: İstanbul Üniversitesi Florence Nightingale Hemşirelik Fakültesi, Abide-i Hürriyet Cad. 34381, Şişli/ İstanbul Tel: 0212 4400000/ 27072 Fax: 02122244950 E-mail: sukranbasgol@gmail.com

\section{$\ddot{O} Z$}

Gelişen dünyada, yaşam kalitesinin yükselmesi fiziksel engelli bireylerin de geleceğe yönelik beklentilerini değiştirmişstir. Fiziksel engelli olmasına rağmen, ebeveyn olmak ve çocuk yetişsirmek isteyen kadın sayısı da artmıştır. Ancak, birçok fiziksel engelli kadın, gebe kaldığında/kalmak istediğinde birçok çevresel ve fiziksel sinırlılıklar, ayrıcı tutum ve davranışlar, tıbbi bakım ve rehabilitasyona ilişkin hizmet yetersizlikleri, eğitim ve ekonomik kisitlllıklar gibi engellerle karşılaşmakta ve gereksinim duydukları sağllk bakım hizmetlerine ulaşamamaktadır. Bu nedenle fiziksel engelli anne adayları doğum öncesi, doğum ve doğum sonrası dönemlerde çeşitli sorunlarla karşılaşmaktadırlar.

Tüm hastaların bakımında etik ve profesyonel mesleki sorumlulukları olan sağlık bakım personeli, fiziksel engelli hasta bakımında da bütüncül yaklaşımı amaçlamalı ve engelli kadınların gereksinim duydukları sağlık bakım hizmetlerinin giderilmesinde gereken desteği ve danışmanlı̆̆ să̆lamalıdır.

Bu derlemede, fiziksel engelli anne adaylarının doğum öncesi, doğum ve doğum sonrası dönemlerde karşılaştıkları sorunlara değinilerek, sağlık bakım profesyonellerinin sorunların çözümündeki rolleri literatür ışığında tartışılacaktır.

Anahtar Kelimeler: Fiziksel engelli kadınlar, fiziksel engelli gebe kadınlar, sağlık bakım gereksinimleri, sağlık bakım profesyonelleri.

\begin{abstract}
In developing world, increase in quality of life has also changed the expectations of people with physical disabilities. Despite being with physical disabilities, there is also an increasing in the number of women who are interested in becoming mothers and raising children. However, many women with physical disabilities when became pregnant/want to get pregnant, usually are faced various obstacles, such as environmental and physical limitations, differential attitudes and behaviors, inadequacies of medical care and rehabilitation services, education and economic constraints, etc. and they can not reach health care services they need. For that reason, mothers with physical disabilities face several issues in their prenatal, delivery and postpartum periods.

Health care provider who has ethical and professional responsibility to provide optimal care for all patients, must aim at a holistic approach to the care of women with physical disabilities. They must provide support and counseling for eliminating the health care needs to women with physical disabilities.

In this review, according to literature, we will discuss issues which women with physical disabilities experience in their prenatal, delivery and postpartum periods, and roles of the health care professionals in solving these problems.

Key Words: Women with physical disabilities, pregnant with physical disabilities, health care needs, health care professionals.
\end{abstract}

\footnotetext{
*Arş. Gör. İstanbul Üniversitesi Florence Nightingale Hemşirelik Fakültesi, **Doç. Dr. İstanbul Üniversitesi Florence Nightingale Hemşirelik Fakültesi Yazının gönderilme tarihi: 25.09.2013

Yazının basım için kabul tarihi: 24.10.2014
} 


\section{GíRiş}

Konjenital olarak veya sonradan herhangi bir nedene bağlı olarak iskelet, kas ve sinir sistemindeki bozukluklar sonucu, bedensel yeteneklerini çeşitli derecelerde kaybeden, toplumsal yaşama uyum sağlama ve günlük yaşamdaki gereksinimlerini karşılamada güçlükleri olan, bu nedenlerden dolayı bakım, rehabilitasyon, danışmanlık ve destek hizmetlerine ihtiyaç duyan bireyler, fiziksel engelli olarak tanımlanmaktadır. Fiziksel engelleri nedeni ile sağlıklı kişilerden farklılaşan, eğitim ve sağlık gibi hizmetlerden gereğince yararlanamayan bu bireyler, tarihin her döneminde toplumda çeşitli güçlüklerle karşılaşmışlardır (T.C. Milli Eğitim Bakanlığı 2008). Bu durum çoğunlukla toplumun engellileri ve dolayısı ile fiziksel engelli kadınların özelliklerini, sorunlarını ve gereksinimlerini yeterince iyi tanımlayamamasından kaynaklanır (Karataş ve Çiftci 2010).

Toplumda genel olarak fiziksel engelli kadınların güçsüz oldukları varsayılmakta ve ebeveynlik de dahil olmak üzere pek çok konuda başarılı olamayacakları düşünülmektedir. Ancak, gelişen dünyada yaşam kalitesinin yükselmesi fiziksel engelli bireylerin de yaşam şartlarını iyileştirmiş, geleceğe yönelik beklentilerini de değiştirmiştir. Fiziksel engeli olmasına rağmen, ebeveyn olmak ve çocuk yetiştirmek isteyen kadın sayısı da artmıştır (Karataş ve Çiftci 2010).

Dünya Sağlık Örgütü'nün verilerine göre gelişmiş ülkelerde nüfusun $\% 10$ 'u, gelişmekte olan ülkelerde ise nüfusun \%12'si engellilerden oluşmaktadır (Özürlüler İdaresi Başkanlığı 2010). Türkiye'de de bu oran, 2002 yılında yapılan Türkiye Özürlüler araştırma sonuçlarına göre \%12.29'dur. Türkiye'de özürlülerin sorun ve beklentilerinin araştırıldığ çalışmada (2010) ise engellilerin yarıya yakınının üreme çağındaki kadınlardan (\%41.4'ü) oluştuğu bildirilmiştir (T.C. Aile ve Sosyal Politikalar Bakanlığı Türkiye İstatistik Kurumu 2010).

Fiziksel engelli kişiler, doğumlarından itibaren ya da engelli bir birey olarak yaşamlarını sürdürmede bir- çok sorunla karşı karşıya kalabilmektedirler. Özellikle üreme dönemindeki fiziksel engelli kadınlar, ergenlik, cinsellik, üreme sağlı̆̆ı, aile planlaması ve gebelik gibi önemli sağlık konularında bakım hizmetlerine gereksinim duyarlar. Ancak, birçok fiziksel engelli kadın, çevresel ve fiziksel sınırlılıklar, ayrıcı tutum ve davranışlar, tıbbi bakım ve rehabilitasyona ilişkin hizmet yetersizlikleri, eğitim ve ekonomik kısıtlılıklar gibi çeşitli engellerden dolayı gereksinim duydukları sağlık bakım hizmetlerine ulaşamamaktadır (Piotrowski ve Snell 2007; Malouf, Redshaw, Kurinczuk ve Gray 2014; Timur, Ege ve Bak1ş 2006). Toplumda, bu bireylerin gereksinimleri genelde bilinmemekte ya da göz ardı edilmektedir. Genellikle fiziksel engelli bireylere önyarg1lı yaklaşılmakta, aseksüel oldukları, gebe kalmayı ve çocuk doğurmayı planlamadıkları ve jinekolojik bakım ihtiyaçları olmadığı varsayılmaktadır (McCabe ve Holmes 2013; Timur ve ark. 2006). Fiziksel engelli bir kadın gebelik düşündüğünde başta kendi aile üyeleri olmak üzere, sağlık personeli ve toplumun olumsuz tepkileri ile karş1laşabilmektedir (Madorsky 1995; Özürlüler İdaresi Başkanlığı 2010). Bu nedenlerden dolayı fiziksel engelli kadınların gebelik ve doğum kararları üzerinde, toplumun ayırıcı tutum ve davranışları, sağlık personelinin engelli kadına olan bakış açıları, ihtiyaç duyulan fiziki ve maddi kaynakların yetersiz oluşu, güvenli doğum ortamının sağlanamayacağı kuşkusu gibi birçok faktörün rol oynadığ1 söylenebilir (Lipson ve Rogers 2000).

Fiziksel engelli kadınların, doğuma ilişkin korku ve belirsizlikleri diğer gebe/gebe kalmak isteyen kadınlarla aynıdır. Ancak fiziksel engeli olan anne aday1 kendi kendine şu soruları sorabilir: "Gebelik engelliliğimi etkileyecek mi ya da engellilik gebeliğimi etkileyecek mi?, Sağlıklı bir şekilde doğurabilecek miyim?, Engelime rağmen, bebeğime iyi bir anne olabilecek miyim?, Engelimden dolayı birileri bebeğimi almaya çalışacak mı?”. Sürekli bu tür sorulara yanıt bulmaya çalışan fiziksel engelli anne adayları, diğer kadınlara göre daha yüksek kaygı ve anksiyete yaşayabilmektedir (Smeltzer 2007). 
Bu derlemede, fiziksel engelli anne adaylarının doğum öncesi, doğum ve doğum sonrası dönemlerde karşılaştıkları sorunlara değinilerek, sağlık bakım profesyonellerinin sorunların çözümündeki rolleri literatür 1ş1ğında tartışılacaktır.

\section{Doğum Öncesi Dönem}

Fiziksel engelli kadın prekonsepsiyonel danışmanlığa geldiğinde, sağlık durumunun en iyi düzeye yükseltilmesi hedeflenmeli, beslenme, kilo kontrolü, sigara- alkolün bırakılması ve aktif ve sekonder semptomların tedavi edilmesi amaçlanmalıdır. Ancak bazı atakların, komplikasyonların ve engele bağlı ortaya çıkan semptomların kontrolü için kullanılması gereken ilaçlar fetüsün sağlığını etkileyebileceğinden, bu kadın için karar vermesi zor bir durum olabilir. Yüksek riskli kabul edilen engelli anne adaylarının yakın takibi bu açıdan son derece önemlidir (Haseltine, Cole ve Gray 1993; Smeltzer 2007).

Prekonsepsiyonel danışmanlığa gelmiş fiziksel engelli bir kadın, sağlık bakım profesyonelleri tarafından "sorumsuz" olarak yargılanabilmektedir. Sağlık personelinin olumsuz tutumları, ayarlanabilir muayene masalarının eksikliği, hastane içi fiziksel sınırlılıklar (dar kapılar, erişilmesi zor banyolar ve odalar) gibi nedenler kadınların sağlık kurumlarına ulaşmasında zorluk oluşturmakta, dolayısıyla gebelikleri öncesi bakım almalarını da engellemektedir. Bu nedenle sağlık bakım profesyonellerinin, fiziksel engelli anne adaylar1nın muayenede nasıl rahatsızlık duyduklarının farkına varmaları ve onların gereksinimlerini belirleyerek, kadınların en iyi şartlarda prenatal bakım almalarını sağlamaları gereklidir (McCabe ve Holmes 2013).

Antenatal kontrollerde fiziksel engelli kadından alınması gereken öyküde; kadının genel sağlık durumunun yanında engellilik durumu, günlük yaşamındaki aktiviteleri, engelli durumuna ilişkin sınırlanan faaliyetleri, kullandığ 1 ilaçlar, gebelik ve engelli durumuna ilişkin endişelerinin sorgulanması da yer almalıdır. Böylece kadının çocuk bakımı konusundaki yeterliliği ve yardım gereksinimi de değerlendirilmiş olacak- tır. Bu süreçte, fiziksel engelli kadının gebelik sırasında değişen bedenine uyumu, yardımcı cihazların kullanımı ve gebelikte farklı oturma pozisyonlarına ilişkin danışmanlık için fizik tedavi uzmanına yönlendirilmesi yararlı olabilir. Engelli kadınlar cinsel istismar açısından yüksek riskli grupta olduklarından, bu kadınların öyküsü alınırken, istismar açısından da değerlendirilmesi son derece önemlidir (Lipson ve Rogers 2000; Rotheram 2007; Smeltzer 2007). Prenatal taramalar sırasında desteğe ve saygı görmeye ihtiyacı olan çoğu engelli kadın için, sağlık personelinin desteğinin çok önemli olduğu da unutulmamalıdır (Piotrowski ve Snell 2007).

Engelli kadınlar çoğu normal kadınlara göre daha az pelvik muayeneye gittiklerinden, ilk gebelik muayenesinin amacını ve kendilerini neyin beklediğini bilmezler. Eğer bir kadın geçmişte hiç pelvik muayene olmadıysa bunun nedeni büyük olasılıkla; ya korkuyor olması ya da cinsel istismara uğramış olmasından kaynaklanmaktadır. Bu nedenle muayeneyi gerçekleştirecek olan sağlık personeli, kadın ile güvene dayalı bir iletişim kurmalı ve muayene sırasında tüm adımları kendisine açıklamalı ve muayene boyunca kad1nın duygularını açıklamasına firsat vermelidir. Ayarlanabilen muayene masalarının kullanılması, kadının tekerlekli sandalyesinden masaya transferinde kolaylık sağlayacaktır. Geleneksel litotomi pozisyonu kadın için uygun değilse ya da kadın istemiyor ise kadının konforu için "diz göğüs" veya "yan uzanma" pozisyonu gibi alternatif pelvik muayene pozisyonları önerilmelidir. Bu nedenle muayene öncesi kadının spastisitesi/ kontraktürünün değerlendirilmesi farklı pozisyon seçeneklerinin denenmesi açısından önemlidir. Antenatal kontrol randevuları da engelli kadının durumuna göre ayarlanabilmelidir (Carty, Conine, Holbrook ve Riddell 1993; Haseltine ve ark. 1993; Madorsky 1995; Smeltzer 2007).

Yüksek riskli gebelik statüsünde kabul edilen fiziksel engelli anne adaylarının, gebelikte engelli durumlarına bağlı çeşitli sağlık sorunları ortaya çıkabilir ya da alevlenebilir. Genellikle de idrar yolu infeksiyon ris- 
ki yüksektir ve gebe kalındığında bu risk artmaktadır. Özellikle nörolojik ve kas-iskelet sistemine ilişkin mesane bozukluğu olan engelli kadınlarda idrar yolu enfeksiyonu (IYYE) daha sık görülmektedir. Tedavi edilemeyen IYY, gebelikte erken doğum eylemini tetikleyebilir. Piyelonefrit öyküsü ya da tekrarlayan IYE olan kadınlara sık izlem, profilaktik antibiyotik tedavisi ve üriner yolu antiseptikleri önerilmektedir. Böyle durumlarda kullanılabilecek ilaçların yararları ve riskleri tartışılmalıdır. Eğer gebelikten önce mesane kontrolü bir problemse, büyüyen fetüsün mesaneye baskı yapması bu durumu daha da kötüleştirecektir (Baschat ve Weiner 2004). Nörojenik bağırsak sorunları olan engelli anne adaylarında ek demir tedavisi verilmesi şiddetli konstipasyona neden olabilir. Bu nedenle, beslenmenin değerlendirilmesi, gebelik ve emzirme için gereken kalorilerinin dikkate alınması büyük önem taşır.
Gebelikte ortaya çıkabilecek diğer sorunlar ve sorunlara yönelik girişimler Tablo 1'de özetlenmiştir. Gebelikte genişleyen karın ve değişen ağırlık merkezi daha büyük bir tekerlekli sandalyeye, uygun ek ekipmana ve ekstra kişisel yardıma ihtiyaç gerektirebilir (Carty ve ark. 1993; Haseltine ve ark. 1993; Smeltzer 2007).

Sağlık personelinin engelli bireyler ile etkin iletişim kuramaması, bireylerin sağlık sisteminden yararlanmasını olumsuz yönde etkileyebilmektedir (Timur ve ark. 2006). Dolayısıyla, fiziksel engelli bireyler için uygun iletişim tekniğinin kullanılması oldukça önemlidir. Özellikle görme engeli olan kadınlarla etkileşimde bulunan tüm sağlik personeli isim ve görevini ayrıntılı olarak kadına açıklamalı, yapılacak testler, doğum ve doğum sonrası süreci kendisine anlatmal1dır. Örneğin, bir kadının işitme kaybı olduğunda, yazma, işitme cihazı takma, dudak okuma veya bir işaret

Tablo 1. Engelli Kadınların Gebelik/ Lohusalık Döneminde Ortaya Çıkabilecek Sorunlar ve Sorunlara Yönelik Girişimler

\begin{tabular}{|c|c|c|}
\hline Sorun & Sorunun Tanımlanması & Soruna Yönelik Girişimler \\
\hline Derin ven trombozu & $\begin{array}{l}\text { Büyüyen fetüs, venöz dönüşü engelleyerek derin ven } \\
\text { tromboz riskini arttırır }\end{array}$ & $\begin{array}{l}\text { - Alt ekstremite; sıcaklık, kızarıklık, ödem, } \\
\text { asimetri açısından değerlendirilir. } \\
\text { - } \text { Bacakların elevasyonu sağlanır. } \\
\text { - } \quad \text { Varis çorabı giyilmesi önerilir. }\end{array}$ \\
\hline $\begin{array}{l}\text { İdrar yolu } \\
\text { enfeksiyonu }\end{array}$ & $\begin{array}{l}\text { Gebelikte artan idrar yolu enfeksiyon riski, özellikle } \\
\text { nörojenik mesane problemi olan engelli kadınlarda } \\
\text { daha fazla artmaktadır. İlerlemiş durumda böbrekleri } \\
\text { etkilemesi ve piyelonefrite neden olması, prematüre } \\
\text { doğumlara ve fetal mortaliteye neden olabilmektedir. }\end{array}$ & $\begin{array}{l}\text { - Sıvı alımının arttırılması, C vitamini tüketimi } \\
\text { önerilir. } \\
\text { - Kızılcık suyu ve kızılcık tabletleri, idrar } \\
\text { pH'ını düşürüp bakterilerin üroepitel floraya } \\
\text { yapışmasını engellediği için önerilir. } \\
\text { - Probiyotik tedavi vajinal floranın onarımını } \\
\text { sağlayarak, idrar yolu enfeksiyonlarının } \\
\text { önlenmesinde önerilir. }\end{array}$ \\
\hline Üriner inkontinans & $\begin{array}{l}\text { Büyüyen fetüsün basıncı ve mesane disfonksiyonları } \\
\text { üriner inkontinans riskini arttırır. }\end{array}$ & - Mesane eğitim programları düzenlenmelidir. \\
\hline Basınç yarası riski & $\begin{array}{l}\text { Gebelikte artan kilo ve bedene bağlı basınç noktaları } \\
\text { değişebilir. Anemisi olan kadınlarda bu risk daha da } \\
\text { fazladır }\end{array}$ & $\begin{array}{l}\text { - Hissetme duyusu azalan kadınlarda kemik } \\
\text { çıkıntıları kontrol edilmeli, deri bütünlüğü } \\
\text { sağlanmalıdır. } \\
\text { - Pozisyon değiştirilmeli, basınçlı bölgeler } \\
\text { yastıklar ile desteklenmelidir. } \\
\text { - Demir desteği ile anemi tedavi edilmelidir. }\end{array}$ \\
\hline Konstipasyon & $\begin{array}{l}\text { Demir alımı ve hareketsizlik konstipasyon riskini } \\
\text { arttırmaktadır. } \\
\text { Nörojenik bağırsak sorunları olan kadınlarda bu risk } \\
\text { daha da artmaktadır. }\end{array}$ & $\begin{array}{l}\text { - Sıvı alımının arttırılması, } \\
\text { - Beslenmenin düzenlenmesi, } \\
\text { - Demir ilacının dikkatli kullanılması, } \\
\text { - Dışkı yumuşatıcıların kullanılması önerilir. }\end{array}$ \\
\hline Düşme/Travma & $\begin{array}{l}\text { Gebelik nedeniyle büyüyen abdomen, kadının ağırlık } \\
\text { merkezinin değişmesine ve denge bozukluğuna } \\
\text { neden olmaktadır. }\end{array}$ & $\begin{array}{l}\text { - Düşme riski altında bulunan kadınlara, } \\
\text { yardımcı cihazları (baston, walker, tekerlikli } \\
\text { sandalye gibi) kullanması önerilir. }\end{array}$ \\
\hline
\end{tabular}

Kaynak: Smeltzer, S.C. (2007). Pregnancy in women with physical disabilities. JOGNN, 36: 88-96. 
dili tercümanı kullanma gibi çeşitli iletişim yöntemleri kullanılabilir. Dudak okumayı kolaylaştırmak için, şeffaf maske kullanımı da bir seçenek olabilir. Kadının isteği üzerine, bir aile üyesine, arkadaşına veya işaret dili tercümanına her zaman iletişime yardımcı olması için izin verilebilir (Carty ve ark. 1993; Haseltine ve ark. 1993; Madorsky 1995).

Yapılan araştırmalarda, çoğu tekerlekli sandalyeli kadın kendilerine gebelikte kilo kontrolü yapılmadığını belirtmişlerdir. Bu nedenle tekerlekli sandalyede oturan fiziksel engelli kadınların da ölçülebildiği tartıların hastanelerde bulunması gereklidir. Eğer kadının kilosu ölçülemiyor ve fundus yüksekliği hesaplanamıyorsa, ultrason ile düzenli olarak büyüyen fetüs hakkında bilgi verilmelidir (Lipson ve Rogers 2000).

Fiziksel engelli anne adayının doğum öncesi dönemde, hastaneye gelerek doğum için gerekli ortamın sağlanabilmesi için doğum ekibiyle birlikte gerekli düzenlemeleri yaptırması son derece önemlidir. Örneğin; işitme veya görme bozuklukları olan kadınlar için hemşire odasina bakan veya ses mesafesinde olan bir oda daha iyi olabilir. Hareket bozuklukları olan kadınlar için kumanda ile ayarlanabilen hastane yatağ 1 , tekerlekli sandalye kullanıcıları için kolayca erişilebilen tuvalet ve duşlar sağlanması güvenli bir ortam oluşturmada büyük katkı sağlayacaktır. Bakım uygulamalarında da girişimler kadına göre düzenlenmelidir. Örneğin; hemiplejik bir kadının sağlam koluna intravenöz hattının yerleştirilmesi kadınının yatak hareketliliği ve tekerlekli sandalyeye transferlerine engel olabileceği göz önünde bulundurulmalıdır (Rotheram 2007; Smeltzer 2007).

Doğum öncesi çeşitli zorluklarla karşılaşan fiziksel engelli kadının, engelinden çok yeteneklerine odaklanılması, kendisiyle etkin iletişim kurulması, açıklayıcı bilgiler verilmesi kadınının kendisini güçlü hissetmesine, özgüveninin ve benlik saygısının artmasına katkı sağlayacaktır (Rotheram 2007; Smeltzer 2007).

\section{Doğum Eylemi}

Fiziksel engelli kadınların, doğuma ilişkin diğer kadınlarla benzer korku ve endişelerinin yanı sıra engel- lerinden kaynaklanan farklı kaygıları da vardır. Yapılan araştırmalarda kadınlar doğum şeklinin kararı konusunda kendilerine danışılmadığını ve vajinal doğum olasılığının değerlendirilmediğini belirtmişlerdir. Genellikle engellerinden dolayı sezaryen doğuma zorlanacaklarından da kaygı duyarlar. Kadınların engelli durumlarının yanında obstetrik endikasyonları değerlendirilerek, sezaryan doğumun anne ve bebek sağlığı açısından yararlı olduğu durumlar da açıklanarak kadınların endişeleri giderilmelidir (Lipson ve Rogers 2000; Smeltzer 2007).

Fiziksel engelli kadınlarda diğer bir kaygı nedeni de anestezidir. Anestezi genellikle güvenli olsa da, spinal kord yaralanmaları, multiple skleroz gibi durumlarda prenatal dönemde anestezi konsültasyonu önerilmektedir (Madorsky 1995; Smeltzer 2007).

Duyusal innervasyonu (T-10 T-12) olan fiziksel engelli gebelerin, doğum başlangıcını tanımlaması zor olabilir. Her kasılmada; batın veya bacaklarda spazmlar, nefes darlığı, idrar sıklığı, başağrısı gibi atipik veya beklenmeyen semptomlar ortaya çıkabilir. Doğum için uygun pozisyonu bulmak önemlidir. Kas zayıflığı doğumda kadının bebeğini itmesine engel olabilir; ancak bu durum kadının obstetrik durumu değerlendirilmeden bir sezaryen endikasyonu olmamalıdır. Pelvik taban hipotonisi vajinal doğum için kolaylaştırıcı bir faktör de olabilir (Smeltzer 2007). T6 seviyesi ve üzerinde spinal kord hasarı görülen kadınlarda otonomik hiperrefleksi görülebilir. Otonomik hiperrefleksi, medulla spinalis T6 ve üzeri travma geçiren olgularda, lezyon seviyesinin altından kaynaklanan rahatsız edici bir uyarıya yanıt olarak gelişen, vazokontrüksiyon ve kan basıncı artışının görüldüğü bir tablodur (Bardak, Erhan ve Gündüz 2008). Perineal şişkinlik, oksitosindeki artış, amniyotomi ve doğumun kendisi otonomik hiperrefleksiyi hızlandırabilir. Bu durum hipertansif ensefalopatiye, serebrovasküler ve intraventriküler kanamaya, maternal ve fetal ölüme yol açabilir. Bu nedenle de spinal kord hasarı görülen tüm kadınların kan basıncının ve nabzının travay sırasında sürekli izlenmesi zorunludur (Baschat ve Weiner 2004; Carty ve ark. 1993). 
Solunum sisteminde kas zayıflığı olan kadınlarda, kan gazı seviyeleri doğum ağrıları başlamadan önce değerlendirilmeli ve oksijen satürasyonu da travay esnasında izlenmelidir. Doğum eyleminde, forseps veya vakum kullanımı sıklıkla tercih edilen yöntemlerdir (Carty ve ark. 1993; Haseltine ve ark. 1993; Smeltzer 2007). Epizyotomi uygulanan kadınlarda emilemeyen dikiş malzemesinin kullanılması infeksiyonların önlenmesinde önemlidir.

\section{Postpartum Dönem}

Fiziksel engelli kadınlar, doğum sonu dönemde diğer kadınlara göre daha fazla süre hastanede kalabilirler. Onlar için hastane odalarına, banyolara ve yeni doğan bebeklerine fiziksel erişilebilirlik önemlidir. Gebeliğe bağlı gelişen fiziksel değişikliklerin gebelik öncesi durumuna geri dönmesi amaciyla fizik tedavi uzmanından egzersiz programı için konsültasyon alınmas1 yararlı olacaktır. Emzirme, diğer kadınlarda olduğu gibi engelli kadınlara da teşvik edilmelidir. Özellikle üst ekstremitesi etkilenen fiziksel engelli kadınlara başlangıçta uygun emzirme pozisyonu konusunda danışmanlık verilmeli, rahat emzirmesi ve bebeğini rahat tutabilmesi için farklı stratejiler (yastıkla destek gibi) belirlenmelidir. Yandan açılabilen beşikler, alçak dolaplar, tekerlekli sandalyenin yanına eklenebilen bebek arabası, annenin bebek bakımı konusunda bağımsız olmasına yardımcı olacaktır. Bebek bakı$\mathrm{m} 1$ ve öz bakım konusunda kullanılabilecek yardımcı cihazların değerlendirilmesi, evde yapılabilecek değişiklikler annenin bebeğine kolayca bakım vermesinde yararlı olabilir. Örneğin yandan açılabilen bebek beşiğinin annenin odasına konulması, kadını bebeğine kolayca ulaşımını sağlayacak, diğer odaya gitmek zorunda birakmayacaktır (Malouf ve ark. 2014; Rotheram 2007; Smeltzer 2007).

Postpartum dönemde fiziksel engelli kadınların ihtiyaçları, gebelikte ortaya çıkan değişimlere ve doğum sonu dönemde artan riskli durumlara bağlı olarak değişkenlik gösterebilir. Romatizmal artrit ve multipl skleroz gibi immün bozukluklar, gebelik sırasında azalıp, postpartum dönemde alevlenirken, sistemik lupus eritematozus gibi diğer immün bozukluklar gebelik sırasında daha da kötüye gidebilir. İlaç tedavisi semptomların kontrolünde önemli olup, emzirme s1rasında sakıncalı olduğundan annenin bu konuda bilgilendirilmesi gereklidir. Günlerini tekerlekli sandalyede oturarak geçiren kadınlarda postpartum süreçte de epizyotomi sık sık gözlenmeli, infeksiyon bulguları açısından değerlendirilmelidir (Lipson ve Rogers 2000; Madorsky 1995; Scott 2005).

Fiziksel engelli kadınlara karşı olumsuz tepki ve önyargılar postpartum dönemde de devam etmektedir. Kadının bu süreçte engelli ve engelli olmayan karışık grupların olduğu lohusa gruplarına katılması yararlı olabilecektir. Sağlık bakım personeli, bu süreçte kadının yeteneklerini ve özgüvenini desteklemeli, ihtiyaçlarını belirleyerek destek sağlamalıdır (Redshaw, Malouf, Gao, Gray ve Ron 2013; Rotheram 2007).

Sağlık bakım personeli engelli hasta bakımında bütüncül yaklaşımı amaçlamalıdır. Engelli hastaların da dahil olduğu tüm hastaların bakımında etik ve profesyonel mesleki sorumlulukları olan sağlık bakım personeli, planlama ve organizasyon ile fiziksel engelli anne adayının ebeveyn yeteneklerinin geliştirilmesinde ve kadının kendine olan güveninin sağlanmasında rehber olmalıdır. Engelli gebe/lohusaya bakım verirken kad1nın ihtiyaçlarını değerlendirebilmeli, bireye özgü uygun girişimlerde bulunmalıdır (Madorsky 1995; Redshaw ve ark. 2013). Sağlık bakım personeli kadın ve ailesinin hastane ve ev ortamındaki ihtiyaçlarını belirlemeli, gerekli düzenlemelerinin yapılabilmesi için destek ve danışmanlık sağlamalıdır. Hasta ve ailesini süreç hakkında bilgilendirerek, bu süreçte engelli ve hasta haklarını kendilerine açıklamalıdır. Sosyal destek alabileceği kurumlar ile işbirliği sağlanmalı, önyarg1sız ve sorgusuz şekilde yanlarında olunmalıdır. Engelli kadınların da diğer kadınlar gibi yaşamdan beklentilerinin ve ebeveyn olma haklarının olduğu unutulmamalidır (Baschat ve Weiner 2004; Rotheram 2007).

Engelli gebe/lohusa bakımında sağlik personeline katk1 sağlayacak anahtar noktalar Tablo 2'de özetlenmiştir. 
Tablo 2. Engelli Gebe/Lohusa Bakımında Sağlık Personeline Katk1 Sağlayacak Anahtar Noktalar

\begin{tabular}{|c|c|}
\hline Temel Başlıklar & Öneriler \\
\hline Çevre ve Malzeme & $\begin{array}{l}\text { - Klinik/ hastanede rampaların } \\
\text { varlığı, geniş ve otomatik kapılar, } \\
\text { kaymaz ve dokunsal tabanlar, } \\
\text { ulaşılabilir banyolar, asansörler } \\
\text { değerlendirilmeli } \\
\text { - Asansörlerde seslendirme } \\
\text { ve dokunsal butonlar uygun } \\
\text { yükseklikte olmalı } \\
\text { - Gündüz ve gece yeterli aydınlanma } \\
\text { sağlanmalı } \\
\text { - Tekerlekli sandalyeden hasta } \\
\text { transferinin kolayca sağlanabilmesi } \\
\text { için muayene masaları değiştirilmeli } \\
\text { - Muayene ve yapılan testler sırasında } \\
\text { sağlik personeli deneyimli ve } \\
\text { yeterli sayıda olmalı, kadının } \\
\text { mahremiyetine ve benliğine dikkat } \\
\text { edilmeli } \\
\text { - Hemşire bankosuna en yakın } \\
\text { odada kalmaları sağlanarak, } \\
\text { istedikleri ziyaretçi yanlarında } \\
\text { bulundurulmalıdır }\end{array}$ \\
\hline Bilgilendirme & $\begin{array}{l}\text { - Her engelli kadının durumuna } \\
\text { uygun sözel ve yazılı açıklama } \\
\text { yapılmalı } \\
\text { - Kadının, eşinin ve kendisine } \\
\text { bakım veren kişinin anlayabileceği } \\
\text { düzeyde bilgilendirme yapılmalı } \\
\text { - Kadının ve bebeğinin, şuan ki ve } \\
\text { gelecekteki ihtiyaçları belirlenmeli } \\
\text { ve giderilmeli }\end{array}$ \\
\hline $\begin{array}{l}\text { Yaklaşımlar ve } \\
\text { Tutumlar }\end{array}$ & $\begin{array}{l}\text { - Engelli kadınların cinsel yaşam ve } \\
\text { gebelik konusunda ilgi ve istekleri } \\
\text { göz ardı edilmemeli, cinsel yolla } \\
\text { bulaşan hastalıklar açısından risk } \\
\text { altında oldukları kabul edilmeli } \\
\text { - Engelli olmayan kadınlara sağlanan } \\
\text { temel sağlık hizmetleri ve tarama } \\
\text { programlarından engelli kadınlar da } \\
\text { hizmet almalı, özellikle cinsellik, } \\
\text { fiziksel ve duygusal istismar } \\
\text { açısından değerlendirilmeli } \\
\text { - Saygı görme ve dinlenme ihtiyacı } \\
\text { olan kadınların, engelleri yerine } \\
\text { kişisel yeteneklerine odaklanılmalı } \\
\text { ve güçlendirilmeli }\end{array}$ \\
\hline
\end{tabular}

Kaynak: Piotrowski, K., Snell, L. (2007). Health needs of women with disabilities across the lifespan. JOGNN, 36: 79-87.

\section{SONUÇ VE ÖNERİLER}

Günümüzde yaşam kalitesinin yükselmesi ile fiziksel engelli bireylerin geleceğe yönelik beklentileri değişmiştir. Nitekim, fiziksel engelli olmasına rağmen, ebeveyn olmak ve çocuk yetiştirmek isteyen kadın sayısı da artmaktadır. Ancak, toplumda fiziksel engelli bireylerin aseksüel oldukları, gebe kalma ve çocuk doğurma gibi planlarının ve jinekolojik bakım gereksinimlerinin olmadığı yönünde önyargılar mevcuttur. $\mathrm{Bu}$ nedenle, sağlık bakım profesyonelleri, bu önyargıların farkında olarak engelli hastaların bakımında da bütüncül yaklaşımı esas almalıdır. Fiziksel engelli kadının gereksinimlerini değerlendirerek, bireye özgü uygun girişimlerde bulunmalıdır.

\section{KAYNAKLAR}

Bardak, A. N., Erhan, B., Gündüz, B. (2008). Pediyatrik medulla spinalis yaralanmalarında otonomik disfonksiyonlar. Türk Fiz Tip Rehab Derg., 54(2): 66-69.

Baschat, A. A., Weiner, C. P. (2004). Chronic neurological diseases and disabling conditions in pregnancy. Welner, S. L., Haseltine, F. (Eds.). Welner's Guide to the Care of Women with Disabilities. Lippincott Williams and Wilkins, Philadelphia, 145-158.

Carty, E., Conine, T., Holbrook, A., Riddell, L. (1993). Guidelines for serving disabled women. Midwifery Today Childbirth Educ., 27: $28-37$.

Haseltine, F. P., Cole, S. S., Gray, D. B. (Eds.) (1993). Reproductive Issues for Persons with Physical Disabilities. Paul H. Brookes Publishing Company, Baltimore.

Karataş, K., Çiftci, E. G. (2010). Türkiye'de engelli kadın olmak: Deneyimler ve çözüm önerileri. Uluslararası Sosyal Araştırmalar Dergisi, 3(13): 147-153.

Lipson, J. G., Rogers, J. G. (2000). Pregnancy, birth, and disability: Women's health care experiences. Health Care for Women International, 21: 11-26.

Madorsky, J. G. (1995). Influence of disability on pregnancy and motherhood. WJM, 162(2): 153-154.

Malouf, R., Redshaw, M., Kurinczuk J. J., Gray, R. (2014). Systematic review of heath care interventions to improve outcomes for women with disability and their family during pregnancy, birth and postnatal period. BMC Pregnancy Childbirth, 14: 58.

McCabe, J., Holmes, D. (2013). Nursing, sexual health and youth with disabilities: A critical ethnography. J Adv Nurs., 30: 1-10.

Özürlüler İdaresi Başkanlığı (2010). Özürlülük araştırmaları: Türkiye özürlüler araştırması temel göstergeleri, http://www.ozida. gov.tr/arastirma/oztemelgosterge.html (11.05.2013).

Piotrowski, K., Snell, L. (2007). Health needs of women with disabilities across the lifespan. JOGNN, 36: 79-87. 
Redshaw, M., Malouf, R., Gao, H., Gray, R. (2013). Women with disability: The experience of maternity care during pregnancy, labour and birth and the postnatal period. BMC Pregnancy Childbirth, 13: 174.

Rotheram, J. (2007). Pregnancy and disability: RCN guidance for midwives and nurses, https://www.rcn.org.uk/_data/assets/pdf file/0010/78733/003113.pdf (11.05.2013).

Scott, R. (2005). Prenatal testing, reproductive autonomy, and disability interests. Cambridge Quarterly of Healthcare Ethics, 14: 65- 82.

Smeltzer, S. C. (2007). Pregnancy in women with physical disabilities. JOGNN, 36: 88-96.
T. C. Aile ve Sosyal Politikalar Bakanlığı Türkiye İstatistik Kurumu (2010). Özürlülerin Sorun ve Beklentileri Araştırması, Ankara.

T. C. Milli Eğitim Bakanlığı Özel Öğretim Kurumları Genel Müdürlüğü (2008). Özel Eğitim ve Rehabilitasyon Merkezi Bedensel Engelli Bireyler Destek Eğitim Programı, Ankara.

Timur, S., Ege, E., Bakış, E. (2006). Engelli kadınların üreme sağlığ1 sorunları ve etkileyen faktörler. C.Ü. Hemşirelik Yüksekokulu Dergisi, 10(1): 51-58. 